\title{
THE PROBLEM OF QUALITY CORRELATION AND EFFICIENCY OF MEDICAL SERVICES AS A FACTOR OF HEALTH ORGANIZATIONS COMPETITIVENESS
}

\author{
Vadim Pashkus, ${ }^{1}$ Natalie Pashkus, ${ }^{2}$ Asya Chemlyakova ${ }^{3}$
}

\begin{abstract}
In the present day, in the context of the toughening of global competition in the field of health care and the efforts that different countries of the world spend on improving the efficiency of the public sector of economy, the problems associated with determining the factors of competitiveness of healthcare organizations come to the forefront. The research conducted by the authors showed that assessing the competitiveness and development potential of medical companies with the Keigan-Vogel positioning map often gives incorrect results. The study showed that a significant part of errors (22-28\%) is due to an incorrect evaluation of the quality and effectiveness of medical services, which necessitates a clear delineation of these concepts. The work shows how these indicators effect the competitiveness of organizations in the health sector and what happens if we do not distinguish between these two concepts.
\end{abstract}

JEL Classification Numbers: I11, H51; DOI: http://dx.doi.org/10.12955/cbup.v5.951

Keywords: medical services; Keigan-Vogel positioning map; quality; effectiveness; competitiveness; public health policy.

\section{Introduction}

Today, the health sector plays a crucial role in the state's economic and social policies. In modern conditions, increasingly more stringent requirements are imposed on healthcare institutions, both on the part of the society interested in improving the quality of life, on the part of the state that finances health development programs, and the work of budget institutions within the framework of the current economic policy. (Altunyan \& Kotcofana, 2016) In this way, healthcare institutions find themselves in a highly competitive environment, and even in global competition, because modern consumer of health services can choose not only between private and public institutions, but also between domestic and foreign ones. (Rybakov et al., 2013) One of the key issues in this area is the correlation of the quality and effectiveness of medical services, which often are mixed by many researchers. To date, there is no single methodology for assessing the quality of medical services - as a rule, quality is replaced by compliance with standards, and the standards themselves are developed either arbitrarily or based on the amounts allocated to the health care system. Therefore, if we ignore the problems of medical services' quality in modern studies, research gaps arise. In modern works a concept is used that is expressed in the classical work of Lanska and Hartz (1998). However, to analyze the competitiveness of organizations in the healthcare sector this, as the authors' research has shown, is clearly not enough.

\section{Methodology}

To analyse the competitive position of companies providing medical services, the breakthrough positioning model proposed in 2000 by Jonathan Keigan and Craig Vogel was chosen (Cagan \& Vogel, 2013) With this model, we can determine the competitive position of the organization, the priority directions of building the company's strategy, and the matching of available resources and capabilities. All companies providing medical services can be divided into 4 types depending on the level of technology, design, and ability to "close" the SET break (generic, kitsch, high-tech, breakthrough). For every type of company, there are winners and losers (in accordance with the modified GE / McKinsey matrix). At the same time, when researching medical companies (unlike universities, museums and other social organizations), a big error arises: research conducted by the authors of the work and the Department of Economic Theory and Economic Policy of St. Petersburg State University in 2007-2016 showed that in the assessment of competitive positions of medical companies, in about $22-28 \%$ of cases there are distorted results because of an incorrect evaluation of the quality of medical services.

This problem is increasing as the state, which sets priorities for the development of the health care system and the ranking of the funding for specific projects and the organizations doing them, and the

\footnotetext{
${ }^{1}$ St. Petersburg State University. v.pashkus@ spbu.ru

${ }^{2}$ Herzen State University. nat.pashkus@gmail.com

${ }^{3}$ Russian State Hydrometeorological University.
} 
society that sets a high standard of quality of medical services, often make very contradictory demands. (Lyakin, 2015) This problem arises from the fact that the aspiration of healthcare institutions for high competitiveness and service demand is not always consistent with their high quality and efficiency from the point of view of the society. (Lanska \& Hartz, 1998) Consequently, it becomes necessary to clarify the concepts of the quality and effectiveness of medical services in their relationship to the competitiveness of the medical institution and the quality and effectiveness of the health system as a whole.

\section{Quality and effectiveness of medical services as factors of competitiveness}

The quality and effectiveness of the provided medical services are the main indicators of their competitiveness in the market and one of the most important indicators of the consumer preferences of medical services, both in the domestic and global markets. It should be understood that the quality and effectiveness of medical services are indicators of consumer preferences only if the consumer is able to understand that they are really high and that they affect the value of their medical service. (Lifits, 2009) The degree of influence on the value of a medical service must be considered both from the point of view of the consumer and from the point of view of its involvement in shaping the further value of a higher-level service, in particular, the quality of the functioning of the health care system.

Usually, consumers tend to pay attention to the perceived qualities of the medical service (Fleming \& Asplund, 2009, p. 96), based on its perceived consumer characteristics and the prestige of their provider. These indicators cannot be completely correlated with real indicators of the quality and effectiveness of medical services. They may not depend on the high value of medical services for direct and indirect consumers (for example, hospitals, or polyclinic complexes, etc...) of medical services. (Lanska \& Hartz, 1998)

The image and prestige of a health care institutions can be created according to a number of external signs of medical services that cause certain attractive associations in the minds of their consumers. This can be a beautiful, sonorous, mysterious name of a service, its technical support, the appearance of the reception rooms, treatment rooms and laboratories, specific image personalities with whom this medical service is associated, an attractive, bright complementary activity of the healthcare institution that involves directly the consumers and many other image indicators (Chesnokova \& Ermakow, 2013). But all of them are not directly related to the quality and effectiveness of the medical service, which can be assessed only by specially trained consumers or by the representatives of health organizations or health authorities themselves.

Moreover, even employees of all kinds of health management organizations and services cannot separate actual quality and performance indicators from their perceived counterparts. For example, the ideal workflow of medical institution, the absence of formal complaints and the exact observance by the medical staff of the service provision rules are associated with the high quality of management of the health care institution and the high quality of the medical services that it teaches. At the same time, in practice it can only testify to the smooth functioning of the bureaucratic system and the full compliance of the declared complex of services, formal requirements, and standards imposed on them. Thus, it is quite difficult to separate perceived quality characteristics from real ones.

The quality and effectiveness of health care services is usually seen as a single and inseparable inherent in them (Valievich \& Parola, 2008, p. 28). At the same time, a situation can be realized when the service will be effective, but will not be high quality, or will be of high quality, but not effective. Therefore, it is necessary to introduce concepts of the quality and effectiveness of medical services and to explore different approaches to their evaluation.

It should be noted that the medical service is a typical public service, and the quality of public services is a set of service characteristics that ensures:

- high value for their consumers;

- possibility of public service consumers participation in the further chain of values formation;

- achieving a high net return from the public sector of the economy for a dedicated cluster of services;

- Low individual consumer risks and risks of the integrity and efficiency of the functioning of the public system, which determine the high level of the population life quality, the growth of human capital and the wealth of a society. 
Consequently, the indicator of the quality of health service is a high level of prevention and recovery of patients without further relapse of diseases with a low level of individual risks of consumers associated with side effects of treatment. This high availability of medical services for all segments of the population, as well as a high level of prevention of serious diseases, aids in the development of a healthy lifestyle and medical culture of the population. The quality of medical services and the quality of the functioning of the healthcare system in general also means a high degree of coherence in the activities of institutions of all types in the timely and full provision of medical services that ensure a high life expectancy and expand the boundaries of the working age of the population.

Medical services are closely associated with a particular institution and even with a specific specialist. At present, medical institutions in Russia are only indirectly linked by the chain of health of the individual. These links are manifested mainly in the availability of regulations for the provision of referrals from polyclinic institutions to obtain routine medical services by hospitals. In addition, some medical services are provided by other medical institutions. For example, ordering specific analysis by one medical institution from another specialized agency for their patients. In fact, there is no effective system of comprehensive provision of medical services, as there is no well-developed system of prevention and detection of serious diseases. Most of the medical services are exclusively of a consumer nature.

However, due to the implementation of a system of compulsory and supplementary medical insurance, an indirect consumer of medical services became the organization which provides the health insurance. Insurance companies that carry medical insurance, on the one hand, assess the quality, formal requirements and completeness of medical care in the customer's case, and on the other hand, regulate the admissible costs under the insurance contract and the patient's actions in obtaining medical care. When implementing health insurance services by several healthcare institutions consistently involved in the provision of health services, the degree of coordination between institutions of different types in the detection, prevention and treatment of patients' diseases is not actually taken into account. As much as possible within the framework of insurance medicine, this problem is taken into account when allocating funds within the allotted sum insured between the various institutions involved in the procedure of medical care. At the same time, if we consider the quality of medical services not from the point of view of insurance conditions but from the point of view of society's needs and ensuring a high quality of life for the population, the problem of coordinating the actions of various medical institutions in the process of identifying, preventing, and treating patients' diseases becomes more important. Indeed, each specific medical service can be provided to the patient in the proper amount, the formal and visible characteristics of the quality of services taken into account by insurance companies are met, and the patient's quality of life not only improves, but may even worsen. Thus, there is a clear discrepancy between the quality of the medical service and its effectiveness, as well as between the quality of a particular service and the quality of comprehensive medical care for the population, i.e. quality of the health system.

It should be noted that a number of medical services are directed not so much to treatment as to the prevention of diseases. In combination with medical measures, preventive measures have a direct impact on the quality of life of the population and the quality of human capital of all economic entities of the country, since only a healthy person can effectively realize his labor functions and take an active vital position necessary for prosperity in the modern economic environment. (Gregova \& Dengov, 2015) Thus, the quality and effectiveness of health services and especially the quality of the functioning of the health care system in a complex has a strong impact on the level of wealth of society. The evaluation of the quality of medical services should take into account the degree of influence of the institution in the characteristics of the human capital of Russian society. At the same time, the effectiveness of medical services has a clearer structure. The effectiveness of medical services is the maximum level of the ratio of the effectiveness of the service (the ability to achieve the stated goals of the implementation of the medical service) to the costs of its creation and implementation.

(Lanska \& Hartz, 1998) It should be noted that this ratio should be realized while maintaining the performance indicators of the health care institution within the given (and normally accepted) limits. In addition, the health services' effectiveness of the service is considered subject to a high degree of satisfaction of the consumers and society with the activities of the health system as a whole. 
Already from the definitions it can be seen that the indicators of quality and efficiency track different characteristics of health services and health system activities. The quality of the medical service is an indicator of the compliance of the service with the requirements and wishes of the consumers (basic and indirect), the compliance of the service with formal requirements and standards, and achieving controlled characteristics of the patient's condition and the results declared by the health care institution in the service certification. At the same time, the effectiveness of the work of a medical institution is the degree to which the goals of the medical institution or the health care system are achieved, with no more than the costs of achieving these results. (Donabedian, 1988) This is why the effectiveness of achieving the goal can be high in the absence of real quality, because the purpose of the service may be different. At the same time, a high quality of service can be achieved, but its effectiveness, both from the consumers of medical services point of view, and from the society's point of view will be low or simply unacceptable. Insurance companies and controlling organizations regulate the formal components and outcomes of providing medical care and providing specific types of medical services. Thus, the quality of the service can meet all the necessary criteria, but it can have only a short-term effect or even no impact on the health and well-being of the patient. Moreover, to justify that the quality of the medical service was inadequate if the formal requirements and visible indicators of its delivery are met is rather difficult, as the examination of the results of medical intervention is also limited by an understanding of all aspects of the quality and effectiveness of the service. The moral and physical costs of the patient, as well as missed opportunities for the timely provision of medical care in the proper amount and composition, are generally not accepted for consideration by either health care institutions or the entities that control their activities.

Correspondence of the quality and effectiveness of medical services is possible only if the targeted services of the health care system are targeted at improving the quality of life of the population, increasing the wealth of the society and strategic priorities for ensuring public health and quality of life, raising human capital, and social orientation of the service, taking into account all possible risks, including in the social sphere. (Kliestik \& Dengov, 2015) Evaluation of these indicators also faces serious problems. This is due to the fact that most of the results of the implementation of medical services are of a qualitative nature and cannot be directly quantified. When assessing these indicators, we must refer to an evaluation system specially developed for them. The method of evaluation will depend on the selected evaluation system, and the choice of the characteristics of the evaluation system depends on the type of information available about the socio-economic system indicators in which the service is being implemented and the service itself. (Chesnokova \& Ermakow, 2013).

Paradoxically, the evaluation of the quality and efficiency of a paid medical service appears simpler if the evaluation criteria do not pursue the global goals of achieving the individual's overall health. If the goal of the medical service is to be effectively sold, that is, to attract the maximum number of consumers who will be satisfied with this purchase, then this case can be approached from the point of view of the ratio of the costs of promotion (creating the image and prestige of the service and health care institution) and the profit received from its implementation. But in this case, there are no positive effects for the society and strategic priorities for improving the quality of the population's life, there is no question, as it is not necessary to observe the real quality of the service. There is a product that needs to be best sold and the same marketing approaches apply to it, which are applicable to any other similar products. In this case, it is necessary to focus exclusively on the perceived quality of medical services and the formation of associations with it that are necessary for the health care institution. Here you can go to profitable indicators, which greatly simplifies the assessment and does not require the construction of integrated quality assessment systems.

In fact, such a situation is possible in which the real and imaginary quality of medical services will be presented in the complex, and the services being implemented will demonstrate high efficiency. But most often, the implementation of such situations in the public sector of the economy is unintended. Usually it is typical for organizations that are recognized leaders in their class. Their image is formed not in the course of specially implemented procedures for promotion, but over a long period.

The positive image of such organizations is formed due to the consumer's evaluation of the value of the results of their activities and the long-term impact of the results of the provision of health services on the health of consumers, which is an important indicator of the real quality of the services of these organizations. Although even for such organizations of the healthcare system, the real quality of 
medical services is estimated by the consumer over a long period of time and extrapolated to the future without changes, which seems unacceptable, since in real life the real quality of services undergoes significant changes without remaining unchanged.

\section{Conclusion}

The analysis showed that the concepts of quality and efficiency, commonly used as synonyms, with respect to medical services, have essential differences. In assessing the competitiveness of health care institutions and in implementing programs for the advancement of health services and institutions themselves, the focus is primarily on the perceived quality of the service and its apparent differences, but only partly on their effectiveness. At the same time, the state health policy is nominally oriented towards achieving the real quality of medical services, but does not explain which priorities in the field of health care are paramount. The guidelines of the state health policy do not explain how the real and perceived quality of medical services, the effectiveness of the results of services provision, the health of the population in the long term, the activities in the health sector, and the quality of life of the population should be agreed upon. Therefore, in order to ensure their competitiveness, healthcare institutions are oriented only to consumers of medical services and are trying to raise the level of the perceived quality of services, following the same requirements of the state, they are forced to focus only on the real quality and efficiency of services, but do not have effective incentives to do so.

As a result, healthcare institutions find themselves in a very complex and contradictory situation, which makes them, in order to survive, give preference to the perceived quality of services, with formal observance of real quality and efficiency. This situation seriously harms not only the health system and its consumers, but also society as a whole and the Russian economy. Thus, it demands acknowledging that the situation in the healthcare sector is rather complicated and contradictory, and it requires serious rethinking and overcoming.

\section{References}

Aliaskarova Zh. A. (2016) New Economy: from the Basics to the Analysis of the Factors Affecting Consumer Demand. Marketing MBA. Journal marketing management firms. Iss. 2. Pp. 7-21.

Altunyan, A., Kotcofana, T. (2016) Global Political and Economical Processes, Monetary Policy of the Bank of Russia and Development of the Russian Economy. Globalization and its Socio-Economic Consequences. 16th International Scientific Conference Proceedings. University of Zilina, Slovak Republic. Pp. 33-40.

Bulina A.O. (2013) Transformation of Institutions in the New Economy. Marketing MBA. Journal marketing management firms. Iss. 3. Pp. 148-166.

Cagan J., Vogel C. M. (2013) Creating Breakthrough Products: Revealing the Secrets that Drive Global Innovation, 2nd ed. Saddle River, NJ: Financial Times PressUpper.

Dengov, V. (2011) Experimental verification of correspondence between adverse selection models and reality. EkonomickoManažérske Spektrum. Iss. 1. Pp. 2-9.

Donabedian, A. (1988) The quality of care: how can it be assessed? JAMA. Vol. 260. Pp. 1743-1748.

Fleming, J.H., Asplund, J. (2009) Human Sigma Managing the employee-customer encounter. - Moscow: Alpina Publisher.$224 \mathrm{p}$.

Gregova, E., Dengov, V. (2015) The Practical Economic Policy in Transition Economies of V4 Countries at the Present Stage of Globalization. Globalization and Its Socio-Economic Consequences, Pts I and II. 15th International Scientific Conference Proceedings. University of Zilina, Slovak Republic. Pp. 150-156

Chesnokova, M.S., Ermakow, Y.V. (2013) Strategic Marketing: Advanced level. St.Petrsburg: KultInformPress.

Kliestik, T., Dengov, V. (2015) Quantitative Approach to Risk as a Social Phenomenon. 2015 5th International Conference on Applied Social Science. Vol. 80. Pp. 28-33.

Lanska, D.J., Hartz, A.J. (1998) Measurement of quality in health care. Neurology. Vol. 50. Iss. 3. Pp. 584-587.

Lifits, I.M. (2009) Competitiveness of goods and services. Moscow: Yurayt Publisher.

Lyakin, A.N. (Ed.) (2015) Economic policy. Moscow: Yurayt.

Rybakov, F.F., Lyakin, A.N., Cisko, S. (Ed.) (2013) Globalization and development of infrastructure. Zilina: University of Zilina

Valievich, R.P., Parolyba, O.B. (2008) Quality management of goods and services. Minsk: Publishing house of the Belarusian State Economics University. 